\title{
INVESTIGATION OF THE TRICYCLE TRACTOR INCLINE INFLUENCE ON ITS STABILITY UNDER THE CONDITIONS OF WORK AT THE OF SLOPE FIELDS
}

Victor Sheychenko Poltava State Agrarian Academy, Ukraine

E-mail: victorseychenko@gmail.com

Gedal Hailis Uman National University of Horticulture, Ukraine E-mail:vsheychenko@ukr.net

Ihor Dudnikov Poltava State Agrarian Academy, Ukraine E-mail: dudnikovigor17@gmail.com

Pavlo Fedirko State Agrarian and Engineering University in Podilya, Ukraine E-mail: rmo@pdatu.edu.ua

Submission: $24 / 11 / 2018$ Revision: 14/12/2018 Accept: 08/02/2019

\section{ABSTRACT}

The theoretical calculations carried out by the authors made it possible to establish the stability conditions for a tricycle tractor on the slope of the field. The research methodology was based on a theoretical solution of a static problem and the establishment of stability of a tricycle tractor depending on its layout and the angle of the field to the horizon. The layout of the tricycle tractor, which has one steerable wheel in front and two wheels in the rear, is considered. The conditions of the steady state of the tractor for the selected scheme are determined. The stability of the tractor will be ensured when the vertical line lowered down from its center of gravity crosses the surface inside the supporting quadrilateral. The surface of the supporting quadrilateral is formed as a result of connecting the outer points of the wheels. The dependence of the influence of the rim width and the wheel radius on the maximum angle of inclination of the tractor with one front wheel is established. 
The scientific problems posed in the work are solved in the developed theoretical bases for determining the stability conditions of a tricycle tractor. The theoretical foundations have been developed taking into account the layout of the tractor and the angle of inclination of the field to the horizon. The dependencies of the maximum angle of inclination of the tractor were theoretically determined, which made it possible to establish the conditions for its safe operation. The scientific background for increasing the safe operating conditions of tricycle tractors has been further developed.

Keywords: stability of a tricycle tractor, tractor weight, slope angle, slope angle of the tractor, conditions of stable balance of a tricycle tractor

\section{INTRODUCTION}

As it is known, the stability of any object on the reference plane will be ensured if the object is located on at least three supports that are not in a straight line (HAILIS et al, 2017) Taking into account the above, if you consider the machine's stability on two wheels (for example, a drill-machine), then this machine must have one more (the third) support. This support may be a tractor hitch component to which the machine is attached. For such a machine, it is important that if operated it does not slide along the sloping plane of the field towards its slope and does not bowl over to the same side (PRYSHLIAK, 2010).

\subsection{Analysis of recent studies and publications}

The work of tractors and agricultural machines depends on their design, the size of the fields where they operate, and the incline of these fields. In this regard, it is important to investigate the effect of the field slope angle to the horizon on the tractor stability during operation (KYRYIENKO et al., 2010).

The paper (USENKO, 2014) presents the results of a study of the stability of a four-wheel tractor, which is located on a field with a slope in either direction. The conditions of non-displacement of the front and rear wheels of the tractor in the direction of the slope have been established. According to these conditions it is necessary that the sum of the maximum frictional forces of both resting pairs of tractor wheels on the ground was greater than the force of the weight that falls on the axle. 
The theoretical substantiation of the condition of transverse stability of a combine harvester during operation on slopes is given in (SMOLINSKYI, 2013). According to the results of the research, the analysis of the position of the static and dynamic stability of the combine on transverse slopes has been carried out and the stability conditions for combines have been established both with and without the frame leveling system. The obtained dependencies are recommended to be used in the design of self-propelled bunker combine harvesters in order to determine its parameters under steady state conditions on the slopes.

The paper (MAKHAROBLIDZE et al, 2017) calculating formula for lateral displacement of the tractor on the; down-hill side of the slope, considering: angle of the slope; mass of the tractor; coefficient of; leading away of wheels; speed of displacement and traveled path, is deduced. In accordance; with this, some traction and exploitation indices of the tractor aggregates are made more exact at; operating on the slope. The research results can be used in developing of new mountain tractors.

High clearance tractors are often operated on rough terrain with high rollover risk, which would result in operator injury. This paper introduces high clearance tractor rollover detection and risk prediction system, developed with multi-sensing technologies and embedded device. Mathematical model was firstly established and coded to calculate the stability index of tested machine. GPS and inertial sensors were utilized to obtain the machine parameters for index calculation. Mobile software was developed with the function of image and sound warning for machine operator. Experiments were conducted to identify the effect of velocity, slope angle, rotation velocities on tractor stability. Obtained results indicated the validity of developed model and prediction system (SUN et al, 2016).

In order to investigate the effects of forward speed, ground slope and wheelground friction coefficient on lateral stability of tractor at the presence of position disturbances, a tractor dynamic model was developed (AHMADI, 2011). In this model two types of instability were considered: instability due to overturn and skid and for each case the stability index was determined. Different geometries and mass specifications of tractor MITSUBISHI-2501D were used to examine the model. According to the results of this model forward speed and ground slope had a reverse effect on all stability indexes. Moreover stability of this tractor was more affected by 
tractor skidding than overturning. Therefore to improve the overall stability of this tractor, preference should be on increasing the tractor stability index derived from skid dynamics of tractor.

The paper (MUNESHI et al, 2016) assumed a possible case that a tractor operator has several spare tires of different types and service condition. Additionally, the ballast weight, track width, and implement position can usually be controlled before operation. A scale model tractor was thus developed allowing changes to these factors. The model tractor was designated to pass over typical farming road surfaces. Moreover, the tractor lateral stability was evaluated in terms of the roll angle, lateral-load transfer ratio, and Phase I overturn index.

Employing the Taguchi method, we arranged experiments and assessed the applicability of the three kinds of indexes regarding tractor Phase I overturn. Results revealed that the roll angle did not well reflect the initiations of overturns. Compared with the lateral-load transfer ratio, the Phase I overturn index had more convincing factorial effects on tractor stability. Further investigation of the suggested tractor configuration supported this conclusion by comparing predicted and experimental results. In practical cases, this approach may provide a reference for engineers to help operators improve driving safety with limited spare parts. An optimized tractor configuration is suggested through this approach.

The paper (GOBBI et al, 2014) the analytical mathematical relations governing the anti-dive and anti-lift characteristic of the farm tractor are derived by considering both the common brake architecture and either the cases of two or four wheel drive systems. The effect of the very complex driveline of farm tractors on antidive and anti-lift characteristic is dealt with. It turns out that, to obtain an anti-dive behavior, in case of four-wheel-drive, the non-statically determined torque distribution between front and rear axles requires a proper tuning of the geometry of the front arms, particularly of their slope.

A geometrical model for predicting the rollover initiation angle and tire contact forces under quasi-static conditions for tractors fitted with front axle pivot is presented (GUZZOMI, 2012). The model uses a kineto-static approach based on two rigid bodies which correspond to: an anterior body, comprising the front axle and wheels (assumed of negligible inertia and mass), and a posterior body, comprising 
the rear wheels and the remaining machine (with significant inertia and mass). As developed, the model is more suited to fixed-chassis tractors with non-massive front wheels and swing axles. The most significant result is that the model suggests that activation of full-brake lock on all four tires may hinder progression into Phase II rollover and this is consistent with the Kutzbach criterion.

This study (SUN et al, 2017) was conducted to develop a numerical program to predict the effective height and width of a safety frame, or tip-over protective structure (TOPS), for a three-wheeled agricultural carrier. To hasten program development, the main algorithm of computation in the original program for a tractor with protective structure laterally rolling over was not modified for this study. The target carrier was assumed to be safe when the successive rollover on the slope was prevented by the adoption of TOPS with sufficient height and width.

Based on catalogue data of commercially available carrier, the accuracy of the developed program was investigated. Results showed a predicted height of TOPS that is reasonable with respect to the carrier dimensions. Then, a small carrier model was constructed to verify the accuracy of analysis by comparing the experimentally obtained result of overturning and the numerical result of the model carrier. Results showed that the developed program had qualitatively sufficient accuracy for predicting the TOPS height. For more precise prediction of the necessary TOPS height for three-wheeled agricultural carrier, a computer program based on the contact physics should be developed to include rolling or sliding of vehicles.

A general model to predict quasi-static articulated tractor instability on a slope has been derived using kineto-static modeling (BAKER; GUZZOMI, 2013). Under simplifying assumptions, it is possible to model fixed-chassis tractors and, in particular, include the effect of front axle-wheel mass. The model is therefore used in this paper to investigate the effect of front body mass on tractor stability and behavior during Phase I rollover.

The results are of particular relevance to four-wheel-drive (4WD) tractors. It is shown that the stability of a tractor depends on the position of the centre of gravity (COG) of the main (posterior) body. For tractors with massive front wheels, tires and beam axles, this COG is likely not to be the same as that found from the standard COG methods currently adopted. 
DOI: 10.14807/ijmp.v10i7.915

Numerous investigations have been made concerning the work of agricultural machines on the field slopes (ARIKO; MOKHOV, 2010), but the issue of a tricycle tractor stability on the slope fields is not sufficiently developed.

\subsection{Statement of the objective and tasks of the study}

The objective of the study is to increase the safety of operating tricycle tractors due to theoretically established conditions for their stable operation on the slopes of the fields.

To achieve this goal, the following tasks were solved:

- to conduct theoretical studies of tricycle tractors under conditions of their operation on the slopes of fields and to determine the influence of the slope angle of the field on the conditions of stable operation of the machine;

- to establish the theoretical dependence of the maximum angle of inclination of the tractor on the width of the wheel rim, wheel radius;

Theoretical studies were carried out using the provisions of higher mathematics, theoretical mechanics, the theory of mechanisms and machines, and mathematical modeling.

\section{RESULTS}

Let's consider the work of a tractor that rests on three wheels under conditions when one of them is a front wheel, and two are the rear wheels. Scheme of this machine is shown in Figure 1. The front wheel of this tractor is a steering wheel.

This tractor has such a peculiarity. Its weight, which falls on the front wheel, should be heavy enough to ensure the pressure of this wheel against the ground when the machine is moving on the road with a slope upward. Under these conditions, due to the transfer of tractor weight to the rear wheels, the load falls on the front wheel.

Under such a location of the tractor wheels, shown in Figure 1, it can be assumed that the $A B D E$ rectangular quadrilateral is located below the tractor, which includes the lower support line $A B$ of the front wheel and the lower lines $D D_{1}$ and $E E_{1}$ of the rear wheels (on the straight line $D E$ ). 
DOI: 10.14807/ijmp.v10i7.915

Inside of this quadrilateral under the condition of a stable condition of a tractor there is a trace of its gravity center $C$, that is, the point of intersection of the vertical axis, passing from the tractor gravity center $C$ down to the intersection with the horizontal surface of the ground. If the gravity center $C$ is located on the ground inside the quadrilateral $A B D E$, the tractor is in a stable condition; if the trace does not lie inside the quadrilateral, it means that there is no stability.

In the Figure 1 it is shown that the weight of the tractor front element, which is indicated as $G_{\mathrm{r}}^{\prime}$, is transmitted to the front wheel. Under the machine operation on the slope of the field, the tractor wheels will turn, and the tractor will also turn. The diagrams of the tractor front wheel rotation on the slope are shown in Figure 2.

If the field is inclined horizontally to a small angle a (Figure 2, a), then the force $G_{\mathrm{T}}^{\prime}$ will be deviating from the median plane dividing the cylindrical part of the wheel rim into two equal parts, also on the angle a (Figure 2, a). The line of force $G_{\mathrm{r}}^{\prime}$ action begins at the point $C_{1}$ and acts vertically downwards to the left of the extreme lower point $A$ of the wheel rim; this means that the force $G_{\mathrm{r}}^{\prime}$ action does not lead to the forward wheel shift to the right.

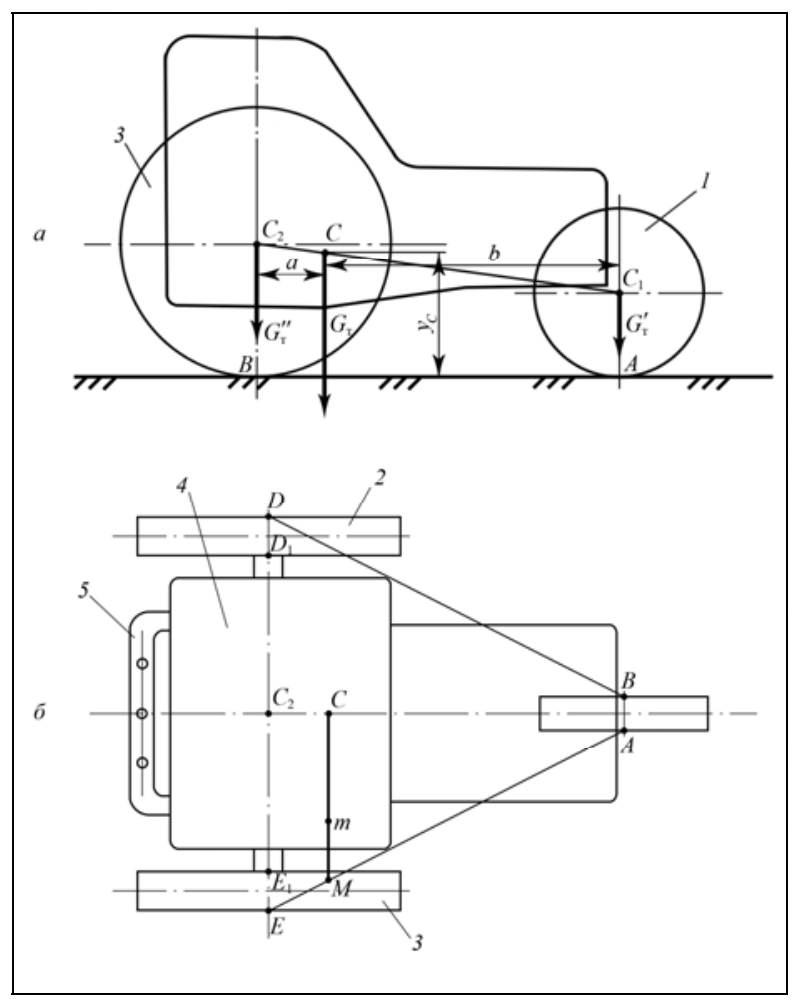

Figure 1. Scheme of the three wheel tractor: 1 - front wheel (steering wheel); 2 - left rear wheel; 3 - right rear wheel; 4 - cabin; 5 - hitch; $A, B, D, D_{1}, E$ and $E_{1}$ are the lower supporting points of the wheel rims. 
If the angle $\alpha$ of the field deviation $E_{2} L_{1}^{\prime}$ upwards from the horizontal line $E_{2} L_{1}^{\prime}$ is larger than the angle $\alpha$ in the previous case (Fig. 2,a), that is, if the angle $\alpha$ is the same as in Fig. 2, $b$, then the vertical force $G_{\mathrm{r}}^{\prime}$, going from point $C_{1}$ downwards (Fig. $2, b)$, crosses the line of the field to the right of the extreme lower point $A$ of the wheel rim.

In this case, it would be possible to roll over the point $A$ of the right wheel, but this is impossible due to the fact that the wheel is connected to the other part of the tractor, which has not yet been brought to such a position as to rollover (for the rollover of the tractor it is necessary, as already being noted, that the trace of the center $C$ of its weight on the ground appeared outside the quadrilateral $A B D E$ in Figure 1).

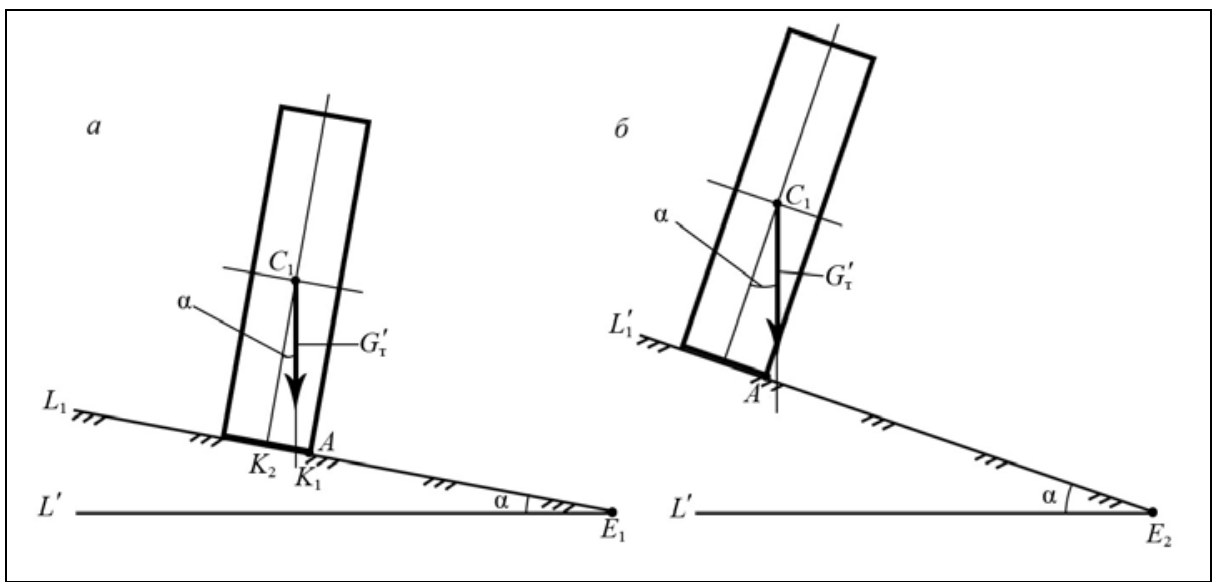

Figure 2. Scheme of the axle load of the sole front wheel of the tractor by $G_{\mathrm{r}}^{\prime}$ force on the field slope at a small angle $\alpha$ (a) and at a large angle $\alpha(b)$ of the field incline.

Under the circumstances where the force $G_{\mathrm{r}}^{\prime}$ of a point $A$ is safe, it does not mean that such a force action is always safe; it is advisable to check this state of force $G_{\mathrm{r}}^{\prime}$ taking into account the above recommendations. Thus, working with such a tractor on the field slopes is better than the scheme in Fig. 2, a shows. It is even better if the force $G_{\mathrm{I}}^{\prime}$ acts on the $C_{1} K_{1}$ or $C_{1} K_{2}$ line on the same Fig. 2, a. The angle $\alpha$ of a field slope incline, under which the vertical line of the force $G_{\mathrm{r}}^{\prime}$ action (Fig. 2) passes through point $A$, is called the limiting angle of the wheel $\alpha_{\text {Kex }}$; it is determined by following dependence: 
DOI: 10.14807/ijmp.v10i7.915

$$
\alpha_{\mathrm{Kex}}=\operatorname{arctg} \frac{b}{2 r_{\kappa}},
$$

where $\mathrm{b}$ is the width of the wheel $\operatorname{rim}, r_{\mathrm{K}}$ is the wheel radius

The $G_{\mathrm{T}}$ force of tractor weight can be divided into two components parallel to it, namely $G_{\mathrm{T}}^{\prime}$ and $G_{\mathrm{T}}^{\prime \prime}\left(\right.$ Fig. 1, a). The force $G_{\mathrm{T}}^{\prime}$ has already been mentioned above. The force $G_{\mathrm{T}}^{\prime \prime}$ is applied at the point $C_{2}$, representing the projection of the $C_{2}$ rear wheels axis on a vertical plane passing through the center of gravity $C_{2}$ of the rear element of the tractor.

Let's assume that if the position of the machine changes, the position of the center of gravity $C_{2}$ does not change, that is, we assume that the moving of materials inside the machine during its movement does not occur, and the distance from the weight center $C_{2}$ to its reference plane and the wheels does not change.

At such a turn of the tractor on the angle $\alpha$, the force $G_{\mathrm{T}}^{\prime \prime}$ will act on the surface of the field perpendicular to this surface with force $G_{\text {тр }}^{\prime \prime}$ (Figure 3) and parallel to the field surface with a sloping force $G_{\mathrm{Ts}}^{\prime \prime}$, that is, the force $G_{2}^{\prime \prime}$ can be expanded into two such components as $G_{\mathrm{Tp}}^{\prime \prime}$ and $G_{\mathrm{Ts}}^{\prime \prime}$ that equal to:

$$
\left.\begin{array}{l}
G_{\text {тр }}^{\prime \prime}=G_{\mathrm{T}}^{\prime \prime} \cos \alpha ; \\
G_{\mathrm{Ts}}^{\prime \prime}=G_{\mathrm{T}}^{\prime \prime} \sin \alpha .
\end{array}\right\}
$$

As a result of action of the $G_{\text {тр }}^{\prime \prime}$ component, the rear part of the machine is pressed against the soil surface (Figure 3), and under the action of the constituent $G_{\mathrm{TS}}^{\prime \prime}$ the machine tends to move to the right, overcoming the resistance to the friction created by the soil in the zones of its contact with the lower wheel surface, where the points $\mathrm{O}_{2}$ and $\mathrm{O}_{3}$ situated (Figure 3 ). All force of soil friction on the lower parts of the rear wheels we indicated as $F$, this force consists of two components $F_{2}$ and $F_{3}$, the component $F_{2}$ operates in the zone of point $\mathrm{O}_{2}$, and component $F_{3}$ operates in the zone of point $\mathrm{O}_{3}$. The component $F_{2}$ equals to $f_{\mathrm{p}} N_{2}$, and the component $F_{3}$ equals to $f_{\mathrm{p}} N_{3}$, where $f_{\mathrm{p}}$ is the friction coefficient at rest, and $N_{2}$ and $N_{3}$ are the normal forces of 
DOI: 10.14807/ijmp.v10i7.915

the soil reaction in the zone of points $\mathrm{O}_{2}$ and $\mathrm{O}_{3}$. Then the condition of the absence of wheel slip on the soil will look like:

$$
F_{2 \max }+F_{3 \max }>G_{\mathrm{r}}^{\prime \prime}
$$

or

$$
f_{\mathrm{p} \max }\left(N_{1}+N_{2}\right)>G_{\mathrm{r}}^{\prime \prime},
$$

where $f_{\mathrm{p} \text { max }}$ is the maximum value of the soil friction coefficient at rest on the wheel rim.

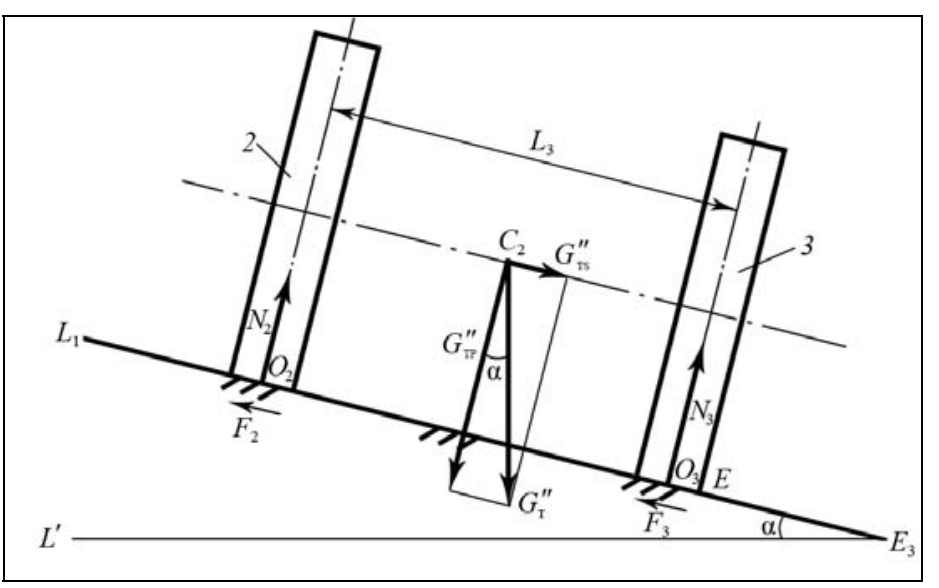

Figure 3. Rear view of a turned three-wheel tractor and forces acting on a transversal vertical plane where the center $\mathrm{C} 2$ is located

Figure 1, 2, 3 and 4 shows the weight force $G_{\mathrm{I}}$ of the tricycle tractor which is applied to the center $C$ of its weight, as well as the components of the force $G_{\mathrm{r}}^{\prime}$ and $G_{\mathrm{r}}^{\prime \prime}$ acting on the point $C_{1}$ of the front wheel axis 1 and at the point $C_{2}$ on the rear axle 2 and 3 . Dependence of forces $G_{\mathrm{r}}^{\prime}$ and $G_{\mathrm{r}}^{\prime \prime}$ on the force $G_{\mathrm{r}}$ and distance $a$ and $b$ between the axes (Fig. 1, a) are given in the equation

$$
\left.\begin{array}{l}
G_{\mathrm{T}}=G_{\mathrm{T}}^{\prime}+G_{\mathrm{T}}^{\prime \prime} \\
G_{\mathrm{T}}^{\prime \prime} a=G_{\mathrm{T}}^{\prime} b
\end{array}\right\}
$$

Taking into account these two equations we find:

$$
\begin{aligned}
& G_{\mathrm{r}}^{\prime}=G \frac{a}{a+b}, \\
& G_{\mathrm{r}}^{\prime \prime}=G \frac{b}{a+b} .
\end{aligned}
$$


DOI: 10.14807/ijmp.v10i7.915

If the three-wheeled tractor is in such position on the field slope shown in Fig. 4 (rear view), then the tractor will be influenced by such forces, which will increase the pressure of the right wheel to the ground, and the pressure of the left wheel on the ground will decrease. Under such conditions a soil pressure force on the lower part of the front wheel also changes a bit (Figure $4, b)$.

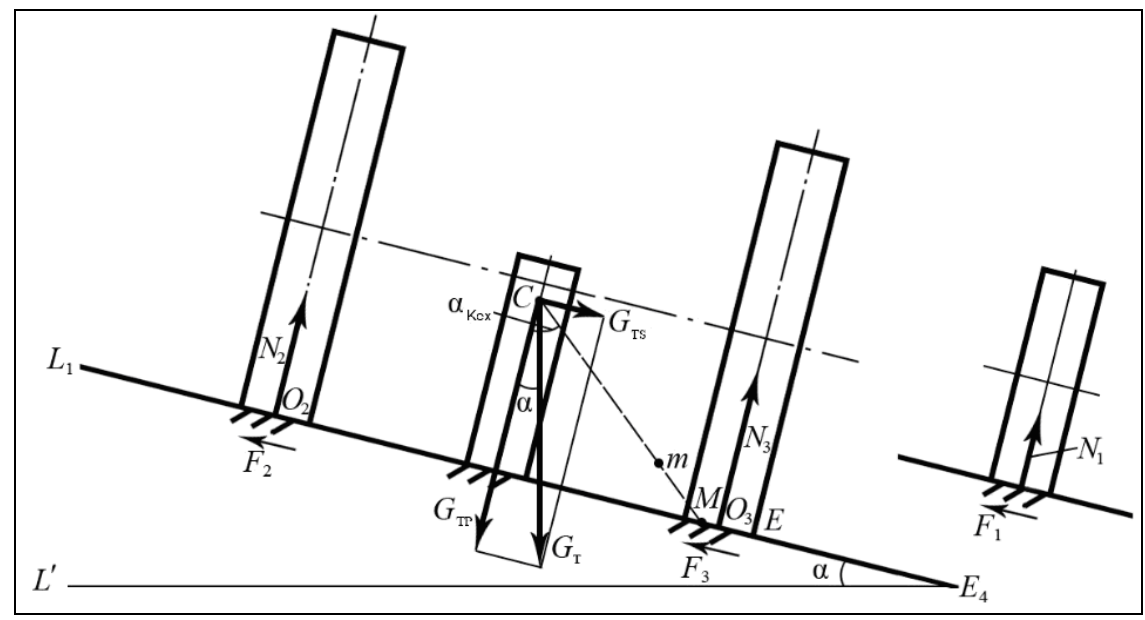

Figure 4. The rear view of a turned three-wheeled tractor and the forces acting on it in a transverse vertical plane, where its gravity center is located.

As can be seen from Fig. 4 on the field slope, the gravity force $G_{\mathrm{T}}$, acting on the whole tractor, is divided into two components $G_{\text {тs }}$ and $G_{\text {тр }}$. The component $G_{\text {тр }}$ presses the tractor to the inclined surface of the field, and the component $G_{\mathrm{TS}}$ seeks to move the tractor to the right and down. This is prevented by friction forces $F_{1}, F_{2}$ and $F_{3}$, acting from the side of the soil on all tractor wheels.

The force $F_{1}=f_{\mathrm{p}} N_{1}, F_{2}=f_{\mathrm{p}} N_{2}$, and force $F_{3}=f_{\mathrm{p}} N_{3}$, where $N_{1}, N_{2}$ and $N_{3}$ are the normal forces of the soil reaction on the rim of wheels 1,2 and 3 , and $f_{\mathrm{p}}$ is the coefficient of soil friction at rest on the wheel rim. Force $G_{\mathrm{T}}$ under these conditions acts vertically down.

The forces $G_{\mathrm{T}}, G_{\mathrm{T}}^{\prime}$ and $G_{\mathrm{r}}^{\prime \prime}$, are in such conditions in a transverse vertical plane.

\section{RESULTS AND DISCUSSION}

According to the results of the theoretical studies of the interaction of the movers of a tricycle tractor with the surface of the field, the conditions for the stability of the tractor depending on the layout and the angle of inclination of the field to the 
DOI: 10.14807/ijmp.v10i7.915

horizon were established. Note that determine stability conditions can be used in the study of self-propelled tricycle tractors, machines and units.

The three-wheel layout has several advantages over the traditional fourwheel. The most important advantages include maneuverability, better control conditions, lower indicators of specific pressure on the soil and metal capacity. For certain operating conditions (mountainous terrain, fields with a complex profile), a three-wheel layout scheme has advantages over a four-wheel one.

For the selected layout scheme, the conditions for the steady state of the tractor are established. The stability of the tractor will be ensured when the vertical is lowered down from its center of gravity and crosses the surface inside the reference quadrilateral. The surface of the supporting quadrilateral is formed as a result of connecting the outer points of the wheels.

The determined conditions of sustainability coincide with the well-known conceptual recommendations for ensuring the steady state of the machine. We distinguish the main ones: an increase in the surface of the supporting, as well as a decrease in the distance from the center of gravity of the machine to the soil surface. The dependence of the influence of the rim width and the wheel radius on the maximum angle of inclination of the tractor with one front wheel is established.

The scientific problems posed in the work are solved in the developed theoretical bases for determining the stability conditions of a tricycle tractor. The theoretical foundations have been developed taking into account the layout of the tractor and the angle of inclination of the field to the horizon. According to the results of the research, the scientific background for increasing the safe operating conditions of tricycle tractors was further developed.

\section{CONCLUSION}

1) The theoretical calculations carried out by the authors made it possible to establish the stability conditions for a tricycle tractor on the slope of the field. The stability of the tractor will be ensured when the vertical line lowered down from its center of gravity crosses the surface inside the supporting quadrilateral. The surface of the supporting quadrilateral is formed as a result of connecting the outer points of the wheel rims. 
2) The dependence of the influence of the rim width and the wheel radius on the maximum angle of inclination of the tractor with one front wheel is established. The dependencies of the maximum angle of inclination of the tractor were theoretically determined, which made it possible to establish the conditions for its safe operation.

3) The theoretical foundations have been developed taking into account the layout of the tractor and the angle of inclination of the field to the horizon. The scientific background for increasing the safe operating conditions of tricycle tractors has been further developed.

\section{REFERENCES}

ARIKO, S. E.; MOKHOV, S. P. (2010) Estimation of stability harvester.

Woodworking: technologies, equipment and management of the XXI century. Available: http://symposium.forest.ru/article/2010/2_tehnology/Ariko.htm.

BAKER, V.; GUZZOMI, A. L. (2013) A model and comparison of 4-wheel-drive fixedchassis tractor rollover during Phase I. Biosystems Engineering, v. 116, n. 2, p. 179-189.

CHAORAN, S.; HIROSHI, N.; SHIGEYOSHI T.; KEIKO, M.; KATSUAKI, O. (2017) Numerical analysis of overturning of a three-wheeled agricultural carrier with a safety frame on a slope. Engineering in Agriculture, Environment and Food, v. 10, n. 4, p. 249-258.

DONG, S.; DU, C.; SHUMAO, W.; XIN, W. (2016) A Dynamic Instability Detection and Prediction System for High Clearance Tractor. IFAC-PapersOnLine, v. 49, n. 16 , p. $50-54$.

GOBBI, M.; MASTINU, G.; PREVIATI G. (2014) Farm tractors with suspended front axle: Anti-dive and anti-lift characteristics. Journal of Terramechanics, v. 56, p. 157-172.

GUZZOMI, A.L. (2012) A revised kineto-static model for Phase I tractor rollover. Biosystems Engineering, v. 113, n. 1, p. 65-75.

HAILIS, G. A.; SHEICHENKO, V. A.; DUDNYKOV, I. A.; MUROVANYI, I. S.; TOLSTUSHKO, N. N.; SHEVCHUK, V. V. (2017) Analysis of the forces acting on the tractor when working on a field slope. Agricultural machines. Scientific Bulletin, v. 32 , p. 121-129.

IMAN, A. (2011) Dynamics of tractor lateral overturn on slopes under the influence of position disturbances (model development). Journal of Terramechanics, v. 48, n. 5, p. 339-346.

KYRYIENKO, M. N.; POLIANSKYI, A. S.; ZADOROZHNY V. V. (2011) Modeling of dynamic stability parameters in terms of the transverse plane tilting equation.

Bulletin of the KhNTUSG named after Petro Vasylenko, Ed. 107, v. 2, p. 22-24. 
MAKHAROBLIDZE, R. M.; LAGVILAVA, I. M.; BASILASHVILI, B. B.; KHAZHOMIA, R. M. (2017) Influence of slip on lateral displacement of the tractor on slope. Annals of Agrarian Science, v. 15, n. 2, June, p. 201-203.

MUNESHI, Z. L.; INOUEB, M. E.; YASUMARU, T. O.; ZHUC, H. Z. (2016) Parameter sensitivity for tractor lateral stability against Phase I overturn on random road surfaces. Biosystems Engineering, v. 150, p. 10-23.

PRYSHLIAK, V. M. (2010) Problems of agriculture and methodological aspects of the study of process automation on the slopes. Scientific Bulletin of NUBiP of Ukraine, v. 144, n. 5, p. 134-142.

SMOLINSKYI, S. V. (2013) Theoretical substantiation of the condition of transverse stability of a grain harvesting combine while working on slopes. Mechanization and electrification of agriculture, v. 1, n. 98, p. 306-313.

USENKO, M. V. (2014) Substantiation of improvement of working details of smallsized machines for cultivating annual crops on slopes. Modern technologies in mechanical engineering and transport, v. 1, p. 121-128. 